\title{
Expression of recombinant human butyrylcholinesterase in the milk of transgenic mice
}

\author{
Dan LU ${ }^{1}$, Shengzhe SHANG ${ }^{1}$, Shen LIU ${ }^{1}$, Ying WU ${ }^{1}$, Fangfang $\mathbf{W U}^{2}$, Tan TAN ${ }^{1}$, Qiuyan LI ${ }^{1}$, Yunping DAI ${ }^{1}$, \\ Xiaoxiang $\mathrm{HU}^{1}$, Yaofeng $\mathrm{ZHAO}^{1}$, Ning LI $(\varangle)^{1}$
}

1 State Key Laboratory for Agrobiotechnology, China Agricultural University, Beijing100193, China

2 College of Animal Science and Technology, Yunnan Agricultural University, Kunming 650000, China

\begin{abstract}
Butyrylcholinesterase (BCHE) is a natural bioscavenger that protects humans against organophosphate toxicity. Due to the limited yield of human BCHE (hBCHE) when purifying from human plasma, it is necessary to find an alternative method to produce this protein. One potential method is to produce transgenic livestock that make modified milk containing high concentration of hBCHE. In this study, we cloned the $h B C H E$ gene into a human lactoferrin (hLF) bacterial artificial chromosome (BAC) construct to make a hLFhBCHE BAC construct. Subsequently, we injected the BAC construct into pronuclei of mouse fertilized embryos and generated transgenic mice. Expression analysis showed that recombinant hBCHE (rhBCHE) was expressed efficiently in the mammary gland of the transgenic mice and the concentration of rhBCHE in the milk of individual mice ranged from $76 \pm 12$ to $159 \pm 28$ $\mathrm{mg} \cdot \mathrm{L}^{-1}$. Protein function tests showed that rhBCHE has the same enzymatic activity as the native hBCHE. Our results pave the way for making transgenic livestock to produce large quantities of rhBCHE.
\end{abstract}

Keywords recombinant human butyrylcholinesterase (rhBCHE), human lactoferrin bacterial artificial chromosome (hLF BAC), transgenic mice, milk

\section{Introduction}

Since the production of the first transgenic mice [1], the use of genetically modified animals has developed rapidly in recent decades, especially for producing recombinant proteins in mammary glands. Numerous proteins have been expressed in the milk of livestock [2,3], and some

Received October 22, 2014; accepted November 5, 2014

Correspondence: ninglcau@cau.edu.cn recombinant proteins with pharmaceutical and biomedical value have been successfully expressed in high quantities in the milk of transgenic animals [4-7]. Most noteworthy is $\operatorname{Atryn}^{\circledR}$, a recombinant version of human antithrombin III produced in the milk of transgenic goats by GTC Biotherapeutics Inc., which has received marketing approval from the European Medicines Agency and the US Food and Drug Administration.

Butyrylcholinesterase (BCHE), also known as pseudocholinesterase, is a natural bioscavenger which protects humans against organophosphate toxicity. The Human BCHE ( $h B C H E$ ) gene is a single copy gene of over $70 \mathrm{~kb}$ located on chromosome 3 [8]. In contrast to acetylcholine, which exhibits specificity toward the neurotransmitter acetylcholine, BCHE can catalyze the hydrolysis of a wide variety of choline and non-choline esters. Through administration of exogenous BCHE, animals can resistant multiple lethal-dose organophosphate intoxication $[9,10]$. BCHE is only present at a concentration of about $1-2$ $\mathrm{mg} \cdot \mathrm{L}^{-1}$, which is insufficient to meet the demand by extracting it from plasma only. Therefore, it is necessary to have an alternative method to produce this protein.

Minigene is a compact version of a gene and it is usually used to detect which part of a gene can be deleted to understand the structure and function of the protein expressed from the gene. A lot of exogenous genes are difficult to be manipulate and express due to their large size. The compact size of minigenes can overcome this problem [11]. In this paper, we replaced a $39.3 \mathrm{~kb}$ DNA fragment of intron 2 with the kanamycin/neomycinresistance gene cassette in $h B C H E$ gene to generate a $h B C H E$ minigene. Human lactoferrin (hLF) with genomic DNA in the hLF bacterial artificial chromosome (BAC) was replaced by the $h B C H E$ minigene, and flanking regions of the $h L F$ gene ( $95 \mathrm{~kb} 5^{\prime}$ and $30 \mathrm{~kb} \mathrm{3}$ ) were used as transcriptional control elements for $\mathrm{hBCHE}$ expression in mice mammary gland. 


\section{Methods and results}

\subsection{Construction of the pBAC-hLF-hBCHE-Neo} expression plasmid

The pBAC-hLF-hBCHE-Neo expression plasmid was constructed by replacing $29 \mathrm{~kb}$ hLF genomic sequence with $20 \mathrm{~kb}$ modified $h B C H E$ genomic DNA on the hLF BAC (Fig. 1). The procedure for modifying the pBAChLF-hBCHE-Neo construct was divided into three distinct steps, which were each verified by PCR and sequencing with the primers listed in Appendix A (Table S1). The first step was a replacement of part of the second intron sequence $(39.3 \mathrm{~kb})$ with the kanamycin/neomycin resis- tance cassette to obtain the hBCHE minigene BAC. Exon 2 of the hBCHE gene was amplified by PCR with plasmid pL452 as the template and transformed into competent SW102 cells containing the hBCHE BAC for recombination. The PCR positive SW102 bacterial cells were made competent for the next procedure. In the second step, an intermediate cloning vector pBR322-hLF-hBCHE was constructed that contained in total four 250-350 bp homologous arms (H1 to H4) amplified by PCR with $\mathrm{hLF} / \mathrm{hBCHE} \mathrm{BAC}$ as the template. The arms $\mathrm{H} 1$ and $\mathrm{H} 2$ were dissociated by Not I digestion to obtain the $20 \mathrm{~kb}$ $h B C H E$ mini genomic coding sequence from ATG to TAA. The linearized plasmid pBR322-hLF-hBCHE was transformed into competent SW102 bacterial cells contained the

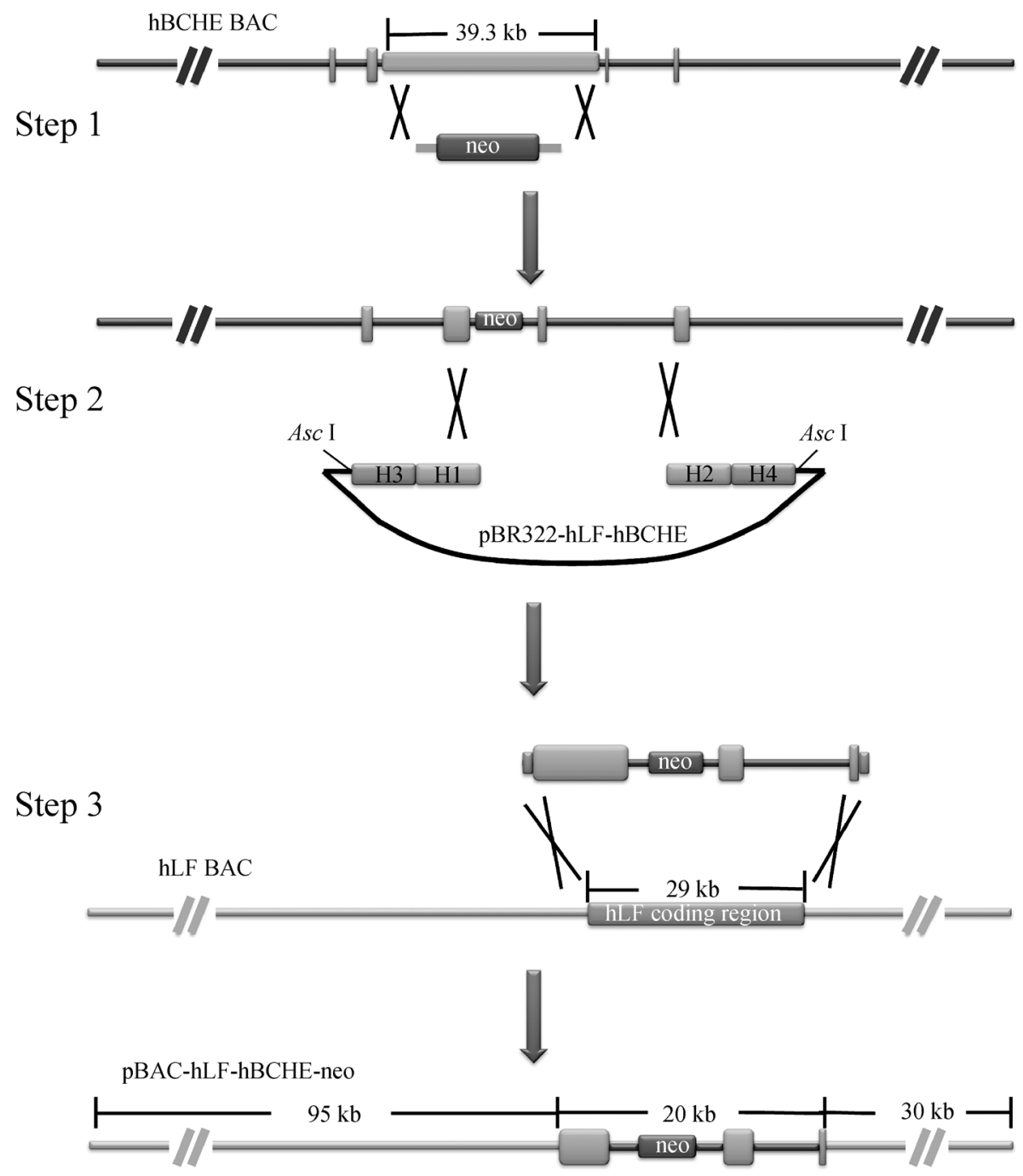

Fig. 1 Sketch of the construction of the pBAC-hLF-hBCHE-Neo expression plasmid. The construction of the pBAC-hLF-hBCHE-Neo expression plasmid was divided into three distinct steps. Step 1: a $2 \mathrm{~kb}$ kanamycin/neomycin resistance cassette flanked by two homologous arms was obtained by PCR and electroporated into competent SW102 cells containing hBCHE BAC to generate the hBCHEminigene BAC; Step 2: arms H1 and H2 were dissociated by Not I digestion to obtain the $20 \mathrm{~kb} h B C H E$ mini genomic coding sequence from ATG to TAA; Step 3: the $29 \mathrm{~kb} h L F$ genomic sequence was replaced with $20 \mathrm{~kb} h B C H E$ mini genomic DNA on the hLF

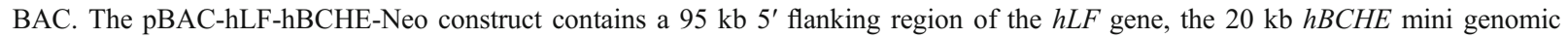
fragment with a kanamycin/neomycin resistance cassette for future SCNT and a $30 \mathrm{~kb} 3^{\prime}$ flanking region of the $h L F$ gene. 
hBCHEminigene $\mathrm{BAC}$, and the positive clones were identified by enzyme digestion. In the final step, the plasmid containing the $20 \mathrm{~kb}$ modified $h B C H E$ genomic DNA fragment was extracted and digested by AscI. The 20 $\mathrm{kb}$ DNA fragment was transformed into competent SW102 cells containing the hLF BAC for recombination. The final modified pBAC-hLF-hBCHE-Neo construct contained a $95 \mathrm{~kb} 5$ ' flanking region of the $h L F$ gene, the $20 \mathrm{~kb} h B C H E$ mini genomic fragment with a kanamycin/neomycin resistance cassette for future SCNT and a $30 \mathrm{kb3}$ ' flanking region of the $h L F$ gene.

\subsection{Generation of transgenic mice}

Transgenic mice were generated by microinjecting circular pBAC-hLF-hBCHE-Neo into the pronuclei of fertilized eggs following the standard microinjection procedure. Two female transgenic founders $\left(\mathrm{F}_{0}-4\right.$ and $\left.\mathrm{F}_{0}-5\right)$ were obtained from 12 mice analyzed by PCR (Fig. 2a). Southern blotting was used to confirm that the transgenes were integrated into the genome of transgenic mice (Fig. 2b). The primer used for the PCR detection was also used as the DNA probe for the PCR using pBAC-hLF-hBCHE-Neo BAC construct DNA as a template. However, the Southern blot analysis showed that only $\mathrm{F}_{0}-4$ was transgenic. Upon sexual maturity, $\mathrm{F}_{0}-4$ was mated with wild type mice and the transgene was successfully transmitted to the offspring. In Fig. $2 b$, the $\mathrm{F}_{1}-7$ is a female offspring from $\mathrm{F}_{0}-4$ and showed a positive band by Southern blotting. The copy numbers of the transgene given in Table 1 were determined using the established method $[12,13]$.

\subsection{Expression of recombinant $\mathrm{hBCHE}$}

To determine if transcription and translation of the transgene (recombinant hBCHE, rhBCHE occurred normally, RT-PCR and western blot were carried out. For RT$\mathrm{PCR}$, total RNA were isolated from lactating mammary gland and other tissues (heart, liver, spleen, lung, kidney, stomach, intestine and muscle) of the $\mathrm{F}_{1}$ generation of line $\mathrm{F}_{0}-4$. Total RNA from lactating mammary gland from wide type mouse was used as a negative control. The primers BCHE-774-F and BCHE-774-R were used to detect the $h B C H E$ mRNA, with a product size of $774 \mathrm{bp}$. The mouse $G A P D H$ gene was used as a control for mRNA extraction and loading. As expected, $h B C H E$ mRNA was detected in the mammary gland of transgenic mice during the middle of the lactation period, but not in other tissues and wild type mammary glands (Fig. 2c).

Milk samples from transgenic mice and wild type mice collected during mid-lactation (days 9-14) were diluted threefold with distilled water and defatted by centrifugation. Milk from wild type mice was used as a negative control and natural $\mathrm{hBCHE}$ standard $\left(300 \mathrm{ng} \cdot \mu \mathrm{L}^{-1}\right)$ was used as a positive control. Three $\mu \mathrm{L}$ for each of the diluted milk samples were loaded into gels. From the western blot result, the founder $\mathrm{F}_{0}-4$ expressed $\mathrm{rhBCHE}$ and showed a positive band with the same protein size as hBCHE standard $(0.9 \mu \mathrm{g})$ (Fig. 2d).

The identification of the oligomeric forms of rhBCHE secreted in milk was performed using non-denaturing and non-reducing activity gels. Milk samples diluted in 0.1 $\mathrm{mol} \cdot \mathrm{L}^{-1}$ potassium phosphate buffer $(\mathrm{pH} 8.0)$ were subjected to electrophoresis on a precast $4 \%-20 \%$ Trisglycine polyacrylamide gel (bio-rad) at $4{ }^{\circ} \mathrm{C}, 10 \mathrm{~mA}$ overnight. The gel was stained with $1 \mathrm{mmol} \cdot \mathrm{L}^{-1}$ butyrylthiocholine iodide as described by Karnovsky and Roots [14]. Wild-type mice milk was included as the negative control and natural hBCHE standard as the positive control. The rBCHE produced in the milk of the transgenic animals migrated as a mixture of dimer and tetramer, and the tetramer was the predominant form (Fig. 2e).

The concentration of rhBCHE was further quantified by Ellman assay. In this assay, a $40 \mu \mathrm{L}$ milk sample, diluted in $0.1 \mathrm{mmol} \cdot \mathrm{L}^{-1}$ potassium phosphate buffer $(\mathrm{pH} 7.0)$, was mixed at room temperature with $10 \mu \mathrm{L} 0.01 \mathrm{mmol} \cdot \mathrm{L}^{-1}$ 5,5'-dithiobis-(2-nitrobenzoic acid) (DTNB) and $260 \mu \mathrm{L}$ $0.1 \mathrm{mmol} \cdot \mathrm{L}^{-1}$ potassium phosphate buffer $(\mathrm{pH} 8.0)$. Two $\mu \mathrm{L}$ of $S$-butyrylthiocholine iodide was added before the absorbance was measured at $412 \mathrm{~nm}$. Changes in absorbance were recorded for at least $6 \mathrm{~min}$. A calibration curve was established using hBCHE standards and used to quantify the rhBCHE concentrations in milk samples. The results showed the expression of rhBCHE ranged from 76.32 to $159.07 \mathrm{ng} \cdot \mu \mathrm{L}^{-1}$ (Table 1 ).

\section{Discussion}

We have successfully produced transgenic mice with hBCHE expressed in milk at an 80-fold higher concentration than that of native hBCHE. This was achieved by replacing a $39.3 \mathrm{~kb}$ DNA fragment of intron 2 with the

Table 1 Expression of recombinant human butyrylcholinesterase in the milk of transgenic mice

\begin{tabular}{lcccc}
\hline No. & Generation & Sex of founder & Copy number & Expression level of rhBCHE/(mg $\left.\cdot \mathrm{L}^{-1}\right)$ \\
\hline 4 & $\mathrm{~F}_{0}$ & Female & 3 & $159.07 \pm 27.79$ \\
7 & $\mathrm{~F}_{1}$ & Female & $1-2$ & $76.32 \pm 11.78$ \\
9 & $\mathrm{~F}_{1}$ & Female & 2 & $124.17 \pm 38.02$ \\
14 & $\mathrm{~F}_{1}$ & Female & $1-2$ & $122.24 \pm 4.79$ \\
\hline
\end{tabular}

Note: values are presented as averages \pm standard deviations. 
(a)

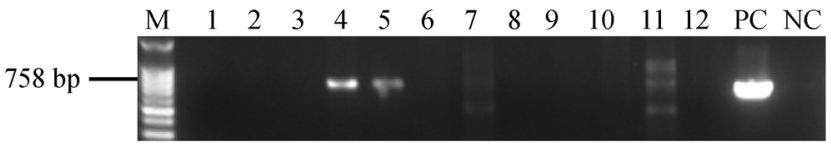

(d)

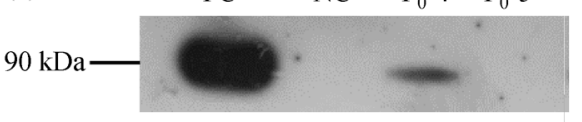

(b)

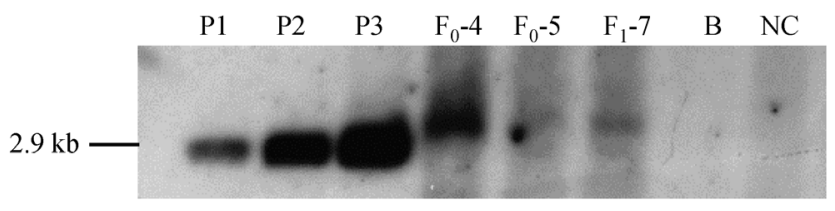

(e)

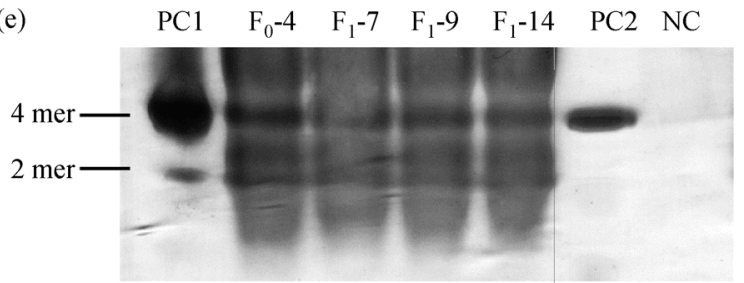

(c)

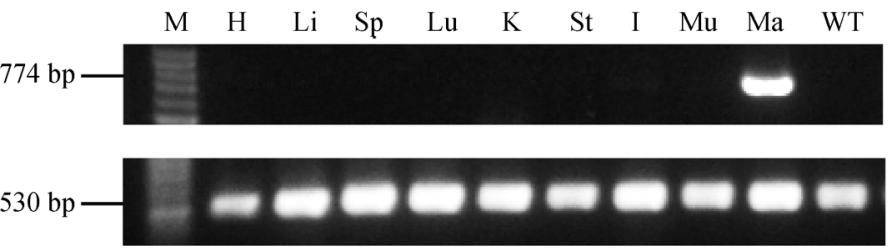

Fig. 2 Molecular characterization of transgenic mice. (a) PCR detection of transgenic founders. M: 100bp DNA ladder; PC: positive control using pBAC-hLF-hBCHE-Neo construct; NC: negative control; lane 1-12: transgenic founders numbered from 1 to 12 ; (b) Southern blot analysis of transgenic founders. Digested genomic DNA of two transgenic founders $\left(\mathrm{F}_{0}-4\right.$ and $\left.\mathrm{F}_{0}-5\right)$, one $\mathrm{F}_{1}$ transgenic mouse from founder line $\mathrm{F}_{0}-4\left(\mathrm{~F}_{1}-7\right)$ and non-transgenic mice. An expected $2.9 \mathrm{~kb}$ band was detected in transgenic samples. B: blank; NC: genomic DNA of non-transgenic mice as a negative control; P1, P2, P3 represent 1, 5 and 10 copies of pBAC-hLF-hBCHE-Neo plasmid, respectively; (c) RT-PCR analysis of transgene expression in transgenic mouse tissues. All tissue RNAs used for RT-PCR were collected during the middle of the lactation period. Mouse GAPDH was used as the RT-PCR internal control. M: 100bp DNA ladder; WT: wild type mouse mammary gland; MG: transgenic mouse mammary gland; H: heart; Li: liver; Sp: spleen; Lu: lung; K: kidney; St: stomach; I: intestine; Mu: muscle; (d) Western blot analysis of recombinant human butyrylcholinesterase (rhBCHE) expression in milk of transgenic mice. The milk samples were collected during the middle of the lactation period, separated by SDS-PAGE and then transferred to nitrocellulose membranes. NC: milk from non-transgenic mice (negative control); PC: hBCHE standard (positive control); $\mathrm{F}_{0}-4$ and $\mathrm{F}_{0}-5$ : diluted milk (1:3) from transgenic founders numbered 4 and 5; (e) non-denaturing gel stained for BCHE activity. PC1: purified plasma hBCHE $(2.5 \mu \mathrm{L})$; PC2: purified plasma hBCHE $(1 \mu \mathrm{L})$; NC: diluted non-transgenic mouse milk $(1: 3) ; \mathrm{F}_{0}-4, \mathrm{~F}_{1}-7, \mathrm{~F}_{1}-9$ and $\mathrm{F}_{1}-14$ : diluted transgenic mice milk (1:3); 2 mer: dimer; 4 mer: tetramer.

kanamycin/neomycin-resistance gene cassette in $h B C H E$ gene to express hBCHE gene without influencing hBCHE protein expression and function.

Previous studies have expressed functional hBCHE in cells [15], mouse and goat mammary gland [5], and it has also have synthesized in plants [16]. Since the $h B C H E$ gene is at least $73 \mathrm{~kb}$, which is large gene and difficulty to manipulate [8], all of the expression constructs in the previous studies used cDNA constructs to express the hBCHE protein. In our study, we modified the $h B C H E$ genomic DNA to generate a convenient cassette for vector construction. We successfully used the modified genomic DNA construct with a $39.3 \mathrm{~kb}$ deletion of part of the second intron to express the rhBCHE in the milk of transgenic mice. Genomic constructs can be expressed more efficiently in transgenic mice than cDNA constructs due to the fact that introns can improve expression of transgenes [17] and even heterologous introns can enhance expression of transgenes in mice [18]. In future research, we will try to construct a vector with the intact $h B C H E$ genomic gene and compare the expression difference with our modified genomic DNA construct.

In addition, to express exogenous gene, a position effect can sometimes cause low level expression or gene silencing [19]. To overcome this, more and more large gene constructs, such as BACs, have been used to express transgenes and produce transgenic animals $[6,13,20]$. BACs contain all the necessary regulatory elements for gene expression and specific sequences such as scaffold/ matrix-attachment regions and locus control regions or insulators [21]. Our previous studies have shown that the hLF BAC regulatory region can effectively regulate the high-level expression of $h L F$ and $h L F$ genes in mice and cows $[6,22,23]$. Consistent with these studies, our results show that hLF BAC regulatory region can regulate the hBCHE expression efficiently. 
In this study, we replaced $39.3 \mathrm{~kb}$ DNA fragment of intron 2 with the kanamycin/neomycin-resistance gene cassette in $h B C H E$ gene to ease the procedure of vector construction. The success of rhBCHE expression is a good example for proteins which possess large gene constructs for which ideal expression levels in animals using cDNA constructs is not achievable.

\section{Conclusions}

We successfully generated transgenic mice expressing rhBCHE in the mammary gland by a modified hLFhBCHE BAC in which $h L F$ genomic DNA was replaced by the $h B C H E$ minigene. The concentration of rhBCHE in the milk of individual mice ranged from $76 \pm 12$ to $159 \pm 28$ $\mathrm{mg} \cdot \mathrm{L}^{-1}$. The rhBCHE protein had the same enzymatic activity as the native hBCHE. Our results illustrate a potential approach for producing large quantities of rhBCHE in the milk of livestock.

\begin{abstract}
Acknowledgements We wish to thank Min Zheng and Meili Wang for their excellent technical assistance and all of our colleagues for their valuable comments and suggestions.
\end{abstract}

Supplementary material The online version of this article at http://dx.doi. org/(doi:10.15302/J-FASE-2014020) contains supplementary material (Appendix A).

Compliance with ethics guidelines Dan Lu, Shengzhe Shang, Shen Liu, Ying Wu, Fangfang Wu, Tan Tan, Qiuyan Li, Yunping Dai, Xiaoxiang Hu, Yaofeng Zhao and Ning Li declare that they have no conflict of interest or financial conflicts to disclose.

All applicable institutional and national guidelines for the care and use of animals were followed.

\section{References}

1. Gordon J W, Scangos G A, Plotkin D J, Barbosa J A, Ruddle F H. Genetic transformation of mouse embryos by microinjection of purified DNA. Proceedings of the National Academy of Sciences of the United States of America, 1980, 77(12): 7380-7384

2. Houdebine L M. Production of pharmaceutical proteins by transgenic animals. Comparative Immunology, Microbiology and Infectious Diseases, 2009, 32(2): 107-121

3. Wheeler M B. Production of transgenic livestock: promise fulfilled. Journal of Animal Science, 2003, 81(Suppl 3): 32-37

4. Wall R J, Powell A M, Paape M J, Kerr D E, Bannerman D D, Pursel V G, Wells K D, Talbot N, Hawk H W. Genetically enhanced cows resist intramammary Staphylococcus aureus infection. Nature Biotechnology, 2005, 23(4): 445-451

5. Huang Y J, Huang Y, Baldassarre H, Wang B, Lazaris A, Leduc M, Bilodeau A S, Bellemare A, Cote M, Herskovits P, Touati M, Turcotte C, Valeanu L, Lemee N, Wilgus H, Begin I, Bhatia B, Rao K, Neveu N, Brochu E, Pierson J, Hockley D K, Cerasoli D M, Lenz D E, Karatzas C N, Langermann S. Recombinant human butyrylcholinesterase from milk of transgenic animals to protect against organophosphate poisoning. Proceedings of the National Academy of Sciences of the United States of America, 2007, 104 (34): 13603-13608

6. Yang P, Wang J, Gong G, Sun X, Zhang R, Du Z, Liu Y, Li R, Ding F, Tang B, Dai Y, Li N. Cattle mammary bioreactor generated by a novel procedure of transgenic cloning for large-scale production of functional human lactoferrin. PLOS ONE, 2008, 3(10): e3453

7. Salamone D, Baranao L, Santos C, Bussmann L, Artuso J, Werning C, Prync A, Carbonetto C, Dabsys S, Munar C, Salaberry R, Berra G, Berra I, Fernández N, Papouchado M, Foti M, Judewicz N, Mujica I, Muñoz L, Alvarez S F, González E, Zimmermann J, Criscuolo M, Melo C. High level expression of bioactive recombinant human growth hormone in the milk of a cloned transgenic cow. Journal of Biotechnology, 2006, 124(2): 469-472

8. Arpagaus M, Kott M, Vatsis K P, Bartels C F, La Du B N, Lockridge O. Structure of the gene for human butyrylcholinesterase. Evidence for a single copy. Biochemistry, 1990, 29(1): 124-131

9. Lenz D E, Clarkson E D, Schulz S M, Cerasoli D M. Butyrylcholinesterase as a therapeutic drug for protection against percutaneous VX. Chemico-Biological Interactions, 2010, 187(1-3): 249-252

10. Lenz D E, Yeung D, Smith J R, Sweeney R E, Lumley L A, Cerasoli D M. Stoichiometric and catalytic scavengers as protection against nerve agent toxicity: a mini review. Toxicology, 2007, 233(1-3): 31-39

11. Warner L E, Chamberlain J S. Minigenes. eLS, 2006. doi:10.1038/ npg.els.0005684 (for online book)

12. Lu D, Li Q, Wu Z, Shang S, Liu S, Wen X, Li Z, Wu F, Li N. Highlevel recombinant human lysozyme expressed in milk of transgenic pigs can inhibit the growth of Escherichia coli in the duodenum and influence intestinal morphology of sucking pigs. PLOS ONE, 2014, 9(2): e89130

13. Bi M, Tong J, Chang F, Wang J, Wei H, Dai Y, Chu M, Zhao Y, Li N. Pituitary-specific overexpression of porcine follicle-stimulating hormone leads to improvement of female fecundity in BAC transgenic mice. PLoS ONE, 2012, 7(7): e42335

14. Karnovsky M J, Roots L. A “direct-coloring” thiocholine method for cholinesterases. Journal of Histochemistry and Cytochemistry, 1964, 12(3): 219-221

15. Millard C B, Lockridge O, Broomfield C A. Design and expression of organophosphorus acid anhydride hydrolase activity in human butyrylcholinesterase. Biochemistry, 1995, 34(49): 15925-15933

16. Geyer B C, Kannan L, Garnaud P E, Broomfield C A, Cadieux C L, Cherni I, Hodgins S M, Kasten S A, Kelley K, Kilbourne J, Oliver Z P, Otto T C, Puffenberger I, Reeves T E, Robbins N, Woods R R, Soreq H, Lenz D E, Cerasoli D M, Mor T S. Plant-derived human butyrylcholinesterase, but not an organophosphorous-compound hydrolyzing variant thereof, protects rodents against nerve agents. Proceedings of the National Academy of Sciences of the United States of America, 2010, 107(47): 20251-20256

17. Brinster R L, Allen J M, Behringer R R, Gelinas R E, Palmiter R D. Introns increase transcriptional efficiency in transgenic mice. Proceedings of the National Academy of Sciences of the United States of America, 1988, 85(3): 836-840

18. Palmiter R D, Sandgren E P, Avarbock M R, Allen D D, Brinster $\mathrm{R}$ L. Heterologous introns can enhance expression of transgenes in mice. Proceedings of the National Academy of Sciences of the 
United States of America, 1991, 88(2): 478-482

19. Wilson C, Bellen H J, Gehring W J. Position effects on eukaryotic gene expression. Annual Review of Cell Biology, 1990, 6(1): 679-714

20. Tong J, Wei H, Liu X, Hu W, Bi M, Wang Y Y, Li Q Y, Li N. Production of recombinant human lysozyme in the milk of transgenic pigs. Transgenic Research, 2011, 20(2): 417-419

21. Giraldo P, Montoliu L. Size matters: use of YACs, BACs and PACs in transgenic animals. Transgenic Research, 2001, 10(2): 83-103
22. Liu Z, Zhao C, Fan B, Dai Y, Zhao Z, Wang L, Zheng M, Feng J, Chen Y, Duan Y, Li N. Variable expression of human lactoferrin gene in mice milk driven by its $90 \mathrm{~kb}$ upstream flanking sequences. Animal Biotechnology, 2004, 15(1): 21-31

23. Liu S, Li X, Lu D, Shang S, Wang M, Zheng M, Zhang R, Tang B, Li Q, Dai Y, Li N. High-level expression of bioactive recombinant human lysozyme in the milk of transgenic mice using a modified human lactoferrin BAC. Transgenic Research, 2012, 21(2): 407-414 